\title{
Reducing Prejudice by Enhancing the Other Rather than the Self
}

\author{
Lisa Legault \\ Deonna Coleman \\ Kayla Jurchak \\ Maria Nefeli Scaltsas
}

Clarkson University

DRAFT

Originally Submitted August 2020

First Revision May 282021

Second Revision July 282021

Accepted August 3, 2021

\section{Citation}

Legault, L., Coleman, D., Jurchak, K., \& Scaltsas, M.N. (accepted). Reducing prejudice by enhancing the other rather than the self. Self \& Identity. 


\begin{abstract}
Some research suggests that self-enhancement is widespread and may exacerbate ingroup favoritism. What if, rather than engaging in self-enhancement, individuals focused on enhancing others? Could enhancing others produce less prejudice than self-enhancement? Three studies tested the effect of selfenhancement versus 'other-enhancement' on prejudice. In Study $1(\mathrm{~N}=95)$, a repeated measures design showed that participants demonstrated less negative affect and less implicit bias after reflecting on another person's positive traits relative to their own. In Study $2(\mathrm{~N}=169)$, we extended this effect to outgroup enhancement. Participants who reflected on an outgroup strength showed less negative affect and less racism than those who reflected on an ingroup strength and those in a comparison condition. Study $3(\mathrm{~N}=380)$ validated these experimental effects by showing that other-enhancement is negatively associated with racism and sexism, whereas self-enhancement is not. Study 3 also examined a theorized antecedent of other-enhancement - humility. We discuss the importance of enhancing others in reducing prejudice.
\end{abstract}

Keywords: self-enhancement; humility; other-enhancement; other-focus; prejudice

Please find all data and code associated with these studies here, or copy this link: https://www.dropbox.com/sh/at1mti2ugn50pmx/AAAshH 4zeH9Oyz Myp39pJWa?dl=0 


\section{Reducing Prejudice by Enhancing the 'Other' Rather than the 'Self'}

Many scholars contend that ingroup favoritism - and to some extent outgroup derogation - may result from the desire to bolster and protect the self or ego (e.g., Hogg \& Abrams, 2007; Turner, Hogg, Oakes, Reicher, \& Wetherell 1987). The centrality of self-enhancement in human motivation (Alicke \& Sedikides, 2011) may have far-reaching consequences for intergroup dynamics. If self-enhancement is ubiquitous and inescapable, as some contend (Sedikides, Gaertner, \& Vevea, 2005; Taylor \& Brown, 1988), then not only is it important to test the effects of self-enhancement on bias and prejudice, but it is also worthwhile to evaluate its complementary process - that of other-enhancement. Whereas self-enhancement has received some attention in intergroup relations, very little research examines what happens when individuals actively enhance or augment others (except see: Rexwinkel, Ellemers, \& Harinck, 2011), and indeed research is needed on how to cultivate positive views of outgroups rather than simply to reduce negative attitudes (Gonzalez, Riggle, \& Rostosky, 2015). In this research, we compare the processes of selfenhancement versus other-enhancement in outgroup attitudes. In doing so, we suggest that otherenhancement may provide a strategy to lessen prejudice in a way that is direct, concrete, and positive.

\section{Self-Enhancement versus Enhancing Others}

The psychological study of the self in relation to others encompasses a very long and sophisticated history of research on the parallel processes of self- versus other-focus (e.g., Aron, Aron, Tudor, \& Nelson, 1991; Markus \& Kitayama, 1991; Schwartz, 2012; Van Lange, De Bruin, Otten, \& Joireman, 1997).

Researchers have conceptualized these complementary phenomena various ways, however, only a few initial studies have begun to address the outcomes of self-enhancement (i.e., thinking favorably of the self; Sedikides \& Alicke, 2012) versus the explicit enhancement of others - that is, the mental process of thinking about others' positive qualities. 
The notion of self-enhancement is a longstanding cornerstone of motivation and identity. From a motivational perspective, it refers to individuals' desire to maximize the positivity of their self-view (Sedikides \& Alicke, 2012). From a trait perspective, self-enhancement comprises both grandiosity and social desirability (Raskin, Novacek, \& Hogan, 1991), and self-enhancers are those who generally have a more favorable view of themselves than they do of others (Alicke, Klotz, Breitenbecher, Yurak, \& Vredenburg, 1996; Asendorpf \& Ostendorf, 1998; Paulhus, 1998). The inclination to self-enhance is extremely widespread (Reeve, 2014; Sedikides \& Alicke, 2019) and classic research goes so far as to suggest that the tendency to see the self in an exceptionally positive light is ubiquitous (Taylor \& Brown, 1988) - due in part to its functional benefits for wellbeing and goal pursuit (Schmitt \& Allik, 2005; O'Mara, Gaertner, Sedikides, Zhou, \& Liu, 2012). For instance, people are more likely to notice, think about, and remember positive information about themselves, and to lose sight of or forget negative self-related information (Sedikides \& Alicke, 2019; Mischel, Ebbesen, \& Zeiss, 1976). Similarly, people consider themselves superior to their peers in various key life domains, including competence, morality, and attractiveness (Alicke \& Govorun, 2005). To date, self-enhancement has been conceptualized as either motivated bias - manifesting as errors in judgment and serving to protect self-esteem - or as a trait, such that some people are generally more self-enhancing than others (Paulhus, 1998). In this research, however, we examine self-enhancement not as motivation or personality but as a basic cognitive process or strategy. That is, we manipulate the mental event of engaging in enhancement, in order to observe its effect on race bias.

Thus, whereas self-enhancement refers to the tendency to see oneself positively, we can think of other-enhancement as its counterpart, that is, the mental process of thinking about others' positive qualities. Human beings require not just the need for self-esteem and to belong and be esteemed by others, but also reciprocally, the need to think well of others in return (e.g., Deci \& Ryan, 2014; Martela \& Ryan, 2019). In this research, we test a strategy to promote thinking positively of others. We define other- 
enhancement as the cognitive process of bringing to mind the positive traits and aspects of others. It is important to note that self-enhancement and other-enhancement are parallel rather than clashing forces. They are not opposite ends of a continuum but rather independent and distinct. Here, we ask a simple question: Does reflecting on the positive qualities of others produce more favorable intergroup attitudes than reflecting positively on the self?

Surprisingly, only a few previous studies have examined the cognitive process of attending to the positive qualities of others. Rexwinkel and colleagues (2011) were first to assess the effects of turning attention to others' positive traits. They found that when participants imagined the positive qualities of a person they were in conflict with, they felt more open-minded toward that person and were more willing to problem-solve with them, compared to when they thought of positive qualities of themselves personally. Scholl, Sassenberg, Scheepers, Ellemers, and de Wit (2017) recently found that the mere cognitive process of situationally focusing attention on others rather than the self increased feelings of personal responsibility toward others.

\section{Enhancement versus Affirmation}

Past research has demonstrated the importance of affirming others by thinking of their core values. For instance, Brown et al. (2019) showed that, much like self-affirmation (acknowledging one's personal values in the face of threat), other-affirmation (acknowledging another person's values) worked to increase young adults' attention to a threatening anti-alcohol message. While affirming others and enhancing are theoretically related processes, it is also important to distinguish them. Whereas enhancement refers only to focusing on positive traits, self-affirmation involves affirming the core self through activation of personal values or important life domains (Sherman \& Cohen, 2002; Steele, 1988). The purpose of self-affirmation is to preserve self-integrity by grounding the self in its core identity (Cohen \& Sherman, 2014). When studying this effect, researchers typically ask participants to list their most important values and then write a few sentences about their top value. They find that acceptance of self- 
threatening information increases when people first affirm their most important value (see McQueen \& Klein, 2006, for a review). Here, we refer to enhancement as the mere activation of strengths or positive traits (of self or other), not about preserving core values per se. Thus, we are not interested in using otheraffirmation as an antidote to image threat, but rather we are interested in the social effects of turning cognitive attention to another person's strengths rather than one's own. Whereas affirmation is a strategy to offset defensive responding by preserving core values (Fein \& Spencer, 1997; McQueen \& Klein, 2006), enhancement is a more basic process of mentally attending to the positive traits of oneself or others.

\section{Enhancing Others is Different than Empathy, Perspective-Taking, Gratitude, and Admiration}

Although studies on the social effects of enhancing others are few (Gonzalez et al., 2015), research on related constructs like empathy, perspective taking, and gratitude is plentiful. Empathy is an emotional response elicited when one grasps the experience of another person in a nonjudgmental way; it is a feeling congruent with that of the target (Davis, 2018). Empathy links to various prosocial outcomes, including the reduction of social bias (Finlay \& Stephan, 2000). While empathy refers to feeling with others, its emphasis is on thoughtfulness and openness to others' hearts and minds - whatever they may be - rather than specifically to the contemplation or appreciation of others' strengths and virtues. Thus, other-enhancement is not empathy, but rather thinking of someone's positive traits or virtues. Similarly, perspective taking is quite distinct from other-enhancement, although both are cognitive processes with potential emotional and motivational consequences, rather than emotional experiences like empathy and gratitude. Unlike other-enhancement, however, perspective taking is imagining what the other might think and feel (Galinsky \& Moskowitz, 2000), and while it can help improve intergroup outcomes (Todd, Bodenhausen, Richeson, \& Galinsky, 2011), it entails projection of the self into the other's perspective thereby retaining focus on the self (Scholl et al., 2017). In contrast, focusing on another person's strengths or virtues means attending only to the other person rather than imagining how the other person might feel. 
Like empathy, gratitude and admiration are other-oriented emotions. However, gratitude and admiration fall specifically into the category of 'other-praising' or 'appreciation' emotions (Algoe \& Haidt, 2009; Fagley, 2016; Ortony, Clore, \& Collins, 1988). Gratitude refers to feelings of thankfulness toward others for the benefits they provide or try to provide (Fagley, 2016). Researchers have not yet examined the intergroup benefits of gratitude, but the interpersonal advantages are numerous - including relationship formation and maintenance (Algoe, Haidt, \& Gable, 2008). With gratitude, however, the focus of appreciation is on what one has, and what others offer the self. The benefactor of gratitude is the self. In contrast, admiration is an emotional response to another person's moral and physical excellence (Algoe \& Haidt, 2009) and more closely resembles our operationalization of other-enhancement. Indeed, where we refer to other-enhancement as the active cognitive strategy of focusing attention to the admirable qualities of another person, admiration is the emotional response to a role model or exemplar (Schindler, Zink, Windrich, \& Menninghaus, 2013). Thus, in the present research, we inquire about the spillover effect of actively turning one's cognitive focus to the strengths of another person rather than the self, rather than the emotional experience of admiration per se.

\section{How Does Enhancement Link to Prejudice?}

Although research on the social effects of enhancing others is lacking, many studies have addressed the role of self-enhancement in driving ingroup favoritism, stereotyping, and prejudice (Fein \& Spencer, 1997; Hogg \& Abrams, 2007; Stangor \& Thompson, 2002). Social identity approaches offer strong theoretical rationale suggesting that efforts to think well of oneself can extend to group identity and promote ingroup favoritism and even outgroup derogation (Abrams \& Hogg, 1988; Tajfel \& Forgas, 1981; Turner et al., 1987). However, many studies have shown inconclusive results (e.g., Abrams \& Hogg, 1988; Rubin \& Hewstone, 1998), likely because they used measures of self-esteem (both personal and collective) to define self-enhancement. High self-esteem in general does not reliably link to prejudice - rather the need to protect, maintain, and bolster self-esteem does (Anderson \& Cheers, 2018; Fein \& Spencer, 1997; 
Stangor \& Thompson, 2002). Thus, despite the well-reasoned suggestion that self-enhancement exacerbates prejudice, experimental evidence is lacking.

In terms of the link between other-enhancement and prejudice, as previously noted there exists evidence of the direct interpersonal benefits of enhancing others (Harinck \& Druckman, 2019; Scholl et al., 2017), but the spillover effects on intergroup outcomes are not yet known. In this research, we test the hypothesis that reflecting on the positive qualities of others (at the interpersonal level) can affect evaluations in an adjacent (i.e., intergroup) domain. That is, we examine whether other-enhancement produces less bias than self-enhancement. In a follow-up study, we test self-enhancement at the group level directly, by attempting to show that momentary focus on a positive quality of the outgroup produces less prejudice than calling to mind a positive quality of the ingroup.

We also explore whether affect mediates the link between enhancement type and prejudice. Reflecting on positive traits (of both self and other) is liable to boost mood. However, we did not have strong justification to hypothesize which type of enhancement would elicit more positive and less negative affect. Past research supports both possibilities. For instance, it is well documented that self-enhancement may help preserve wellbeing (e.g., O'Mara et al., 2012; Sedikides \& Alicke, 2019). At the same time, research also suggests that benevolence toward and appreciation of others connects to positive emotional experience (Martela \& Ryan, 2016), and that other-praising emotions like gratitude serve a mood-boosting function (McCullough, Tsang, \& Emmons 2004). Furthermore, the link between affect and prejudice is not straightforward. Some work suggests that positive affect can facilitate positive outgroup responses when they are coupled or congruent - that is, positive affect reduces prejudice when prejudice reduction goals are made accessible (Huntsinger, Sinclair, Dunn, \& Clore, 2010). Conversely, other work shows that those in more positive moods tend to rely more on stereotypes and biases, which may serve to exacerbate prejudice (Lambert, Khan, Lickel, \& Fricke,1997; Schwarz \& Clore, 2007). Thus, on one hand we reasoned that reflecting on the positive traits of others might elevate mood relative to self-enhancement, and this 
positive affect might facilitate more positive attitudes toward the outgroup. On the other hand, if otherenhancement were to be less beneficial for mood than self-enhancement, we reasoned that this relative neutrality in affect might help to account for more egalitarian responding. We explored these alternatives by testing whether affect accounted for any effect on prejudice.

\section{The Current Studies}

To respond to the lack of experimental evidence of the effect of self-enhancement on prejudice and to contribute to burgeoning research on 'other-enhancement', we compare the effects of selfenhancement and other-enhancement on race bias. Specifically, we are interested in whether engaging in positive self-reflection elicits greater bias than reflecting on another person's positive attributes. Past work shows that thinking about others' positive qualities increases interpersonal openness relative to thinking positively of oneself (Rexwinkel, et al., 2011). Moreover, feelings of admiration for others leads to self-expansion, or the desire to improve the self (Schindler, Paech, \& Löwenbrück, 2015). In contrast, thinking highly of the self sometimes connects to the derogation of others (Fein \& Spencer, 1997; Stangor \& Thompson, 2002). Two complementary studies explore this question experimentally. In Study 1, we used a repeated measures design; participants completed both a self-enhancement and an otherenhancement exercise and implicit bias was subsequently recorded in both conditions. In Study 2, we looked at between group differences and included a comparison condition to infer whether self- versus other-enhancement differed from an objective self-evaluation condition. We expected that otherenhancement would yield lower prejudice than self-enhancement and objective self-evaluation. In both studies, we assessed state affect as a function of self- versus other-enhancement, and tested whether this might explain the connection between enhancement type and prejudice.

Study 3 was intended to provide some construct validity for the findings in Studies 1 and 2, as well as to explore a key theoretical antecedent of other-enhancement - humility. We assessed interrelations among self- versus other-enhancement tendencies (at the individual difference level) and two forms of 
prejudice - racism and sexism. We also theorized that dispositional humility would be an important theoretical antecedent of the tendency to be pro-self or pro-other. Dispositional humility involves a balanced and objective view of the self, as well as a lack of arrogance and appreciation of other people's worth (Chancellor \& Lyubomirsky, 2013; Davis et al., 2011; Tangney, 2002). We therefore reasoned that humility would link positively to other-enhancement and negatively to self-enhancement tendencies, and that other-enhancement (but not self-enhancement) would, in turn, inversely connect to racism and sexism.

\section{Study 1: Effect of Self-Enhancement vs. Other-Enhancement on Implicit Race Bias}

In this experiment, we used a repeated measures design to manipulate the target of enhancement (i.e., self or other), and to measure the effect on implicit race bias. All participants reflected on a positive personal trait and a positive trait of someone they know. We measured state affect and race bias after each reflection exercise. We expected that turning attention to the strengths of others would produce less outgroup bias than focusing on one's own strengths.

\section{Method}

\section{Design and Procedure}

Participants visited the lab to complete two enhancement exercises, as well as subsequent measures of affect and race bias. We used a fully repeated measures design with two conditions, where all participants were exposed to all measures twice. Because we were interested in activating personalitybased merits or virtues, we requested that participants focus on a personality or character attribute (e.g., "generous") of themselves and someone they know, rather than a physical feature (e.g., "nice smile" or "athletic"). After each reflection, we measured state mood and implicit bias. We counterbalanced the order of the type of reflection across participants and, in order to reduce carryover effects across conditions, we asked participants to engage in an unrelated distraction and absorption exercise before 
moving to the second reflection task; they spent 5-10 minutes between conditions interpreting a piece of artwork (they wrote 4-6 sentences about it, on average).

\section{Participants}

An a priori power analysis suggested that we would require 38 participants for this design and analysis, in order to detect a moderate effect $(f=.25)$ with adequate power (0.85). We based our effect estimate on a recent meta-analysis characterizing the average effect of motivational strategies to manipulate or reduce implicit bias (Forscher et al., 2019). Undergraduates ( $N=95$ ) from a small northeastern university participated for course credit. The sample included 33 individuals who identified as female and 62 who identified as male. Participants were mostly American Citizens (92.6\%) and white $(91.6 \%)$, with a mean age of 19.600 years $(S D=3.574)$. We omitted six participants from further analyses because they either failed to identify a specific positive trait of someone else (e.g., "he's my friend") or because they ignored instructions and chose to focus on physical characteristics (e.g., face or body) of themselves and/or others. The final sample included 89 participants whose reflections appeared to be meaningful and of high quality (see first paragraph of preliminary analysis section).

\section{Measures}

Manipulation: Self-Enhancing vs. Other-Enhancing Reflections. As stated, participants identified and reflected on a personal strength and a strength of someone they know. This manipulation consisted of three parts. First, participants identified a single, specific personality strength; we explicitly asked them to write down a character attribute. In the 'other' condition, we asked participants to write down the first name of the person about whom they were thinking. We then asked them to write a paragraph explaining why and how this attribute describes them/the other person, using an example if possible. Thus, all participants completed both reflections. After each reflection, we measured state affect, and then asked participants to write down the attribute again, as a reminder, before measuring race bias. All experimental materials are published in the online appendix. 
State Affect. We measured affect using six items from the Positive and Negative Affect Schedule (Watson, Clark, \& Tellegen, 1988). After each enhancement exercise, participants rated the extent to which they felt "distressed", "hostile", "worried", "ashamed", "nervous", and "afraid" on a scale from 1 (not at all) to 5 (extremely). This measure has demonstrated good validity and reliability (Crawford \& Henry, 2004), and in the present sample, internal consistency was adequate ( $\alpha=.873$ ).

Implicit Race Bias. We measured implicit race bias after each enhancement exercise using the Race-Face Implicit Association Test (IAT; Greenwald, McGhee, \& Schwartz, 1998), which assesses the strength of association between racial categories on one hand, and positive and negative attributes on the other. Past research on the IAT effect has suggested that people tend to sort stimuli with relative speed and accuracy when Black-Unpleasant and White-Pleasant labels share the same response keys (compared to Black-Pleasant and White-Unpleasant)-suggesting that these concept pairings are more strongly associated (e.g., Greenwald et al., 1998; Greenwald, Poehlman, Uhlmann, \& Banaji, 2009). We included all practice trials and test trials in IAT scores, in order to offset learning effects resulting from two consecutive administrations of the IAT (Nosek, Greenwald, \& Banaji, 2005). The IAT demonstrates good reliability (Greenwald et al., 2009). Here we use the D scoring algorithm calculate implicit bias calibrated by each respondent's latency variability, thereby reducing confounds associated with general cognitive skill and speed of responding (Greenwald, Nosek, \& Banaji, 2003).

\section{Results and Discussion}

\section{Preliminary Analysis}

The quality of participants' reflections appeared generally high. Participants described themselves as "caring/kind/empathic" (33\%), "hard-working/determined" (21\%), as well as a wide range of other attributes, including thoughtful, creative, polite, insightful, adventurous, agreeable, frank, fun loving, and humble. They described others as "caring/kind/loving/understanding/supportive" (60\%), "hardworking/focused/determined" (12\%), and "intelligent" (4.5\%), as well as various other adjectives 
including forgiving, outgoing, funny, loyal, and honest. Participants wrote approximately two sentences justifying how they/others exemplify the identified trait.

We screened data for measured variables prior to analysis and removed one extreme outlier on the IAT (more than four standard deviations below the mean; from the other-enhancement condition). We present descriptive statistics (i.e., cell means) for the measured variables in Table 1.

Table 1. Descriptive Statistics for Measured Variables in Study 1

\begin{tabular}{l|llll}
\multicolumn{1}{l}{} & $\begin{array}{l}\text { Negative } \\
\text { Affect (Self) }\end{array}$ & $\begin{array}{l}\text { Negative Affect } \\
\text { (Other) }\end{array}$ & $\begin{array}{l}\text { IAT D Score } \\
\text { (Self) }\end{array}$ & $\begin{array}{l}\text { IAT D Score } \\
\text { (Other) }\end{array}$ \\
\hline Mean & 1.838 & 1.594 & .398 & .252 \\
Standard Deviation & .723 & .544 & .338 & .417 \\
Skewness & 1.013 & .706 & -.028 & -.080 \\
Kurtosis & & & & \\
& .624 & -.489 & .131 & -.679
\end{tabular}

Note. Theoretical range for affect score is 1-5.

\section{Main Analysis}

We tested the hypothesis that focusing on another person's positive attributes would produce less bias than focusing on one's own positive attributes. We used a repeated measures ANOVA to assess the effect of self-enhancement vs. other-enhancement on negative affect and race bias (see Table 1 for cell means $)^{1}$. Data and code are available here. Results showed that when participants focused on the positive attribute of another person, they demonstrated less negative affect, $F(1,87)=22.599, p<.0001, \eta_{p}{ }^{2}=.206$, and less race bias, $F(1,87)=11.576, p=.001, \eta_{p}{ }^{2}=.117$, compared to when they reflected on their own positive attribute².

\footnotetext{
${ }^{1}$ We tested whether order of presentation of the task affected implicit bias. We did not find an order effect on implicit bias in either the self-enhancement or other-enhancement condition ( $F=.343$ and $F=.568$, respectively). ${ }^{2}$ We also recalculated this analysis with non-white participants (including two Black, two East Asian, and two South Asian participants) removed, since the IAT measured white vs. Black preference. This did not change the pattern or significance of results, $F(1,81)=23.304, p<.0001, \eta_{p}{ }^{2}=.223$ (for affect), and $F(1,81)=8.301, p=.005, \eta_{p}{ }^{2}=$ .093 (for race bias).
} 
To test whether affect might explain the effect of condition on race bias, we first assessed whether changes in affect were associated with changes in implicit bias. The relationship was not significant, $r(88)=.202, p=.059$, but we nonetheless probed for an indirect effect of negative affect using MEMORE (Montoya \& Hayes, 2017), a procedure that estimates total, direct, and indirect effects in a repeated measures design based on path analysis. Affect did not mediate the effect of enhancement on bias, $\mathrm{B}=-.039, \mathrm{SE}=.032,95 \% \mathrm{Cl}[-.103, .022]$. The direct effect of other-enhancement on race bias remained after controlling for changes in affect across conditions, $\mathrm{B}=-.107, \mathrm{SE}=.048,95 \% \mathrm{Cl}[-.204,-.011], \mathrm{t}(85)=-$ $2.208, p=.030$.

Study 1 suggests that when people focus on the strengths of others, they show less implicit bias than when they focus on their own strengths, even when controlling for changes in affect. In Study 1, we used a repeated measures design to compare self- versus other-enhancement within participants, thus controlling for individual differences across participants. However, we did not include a comparison condition to determine whether other-enhancement differed from a non-self-enhancing baseline. Therefore, Study 2 included a comparison group of counterbalanced (i.e., objective) self-evaluation. Moreover, because self-enhancement operates at both the personal and social level (e.g., Abrams \& Hogg, 1988; Tajfel \& Forgas, 1981), we also extended the Study 1 paradigm from the (inter)personal level to the group level, such that we asked individual group members to either enhance their ingroup or enhance the outgroup, before measuring outgroup prejudice. Thus, studies 1 and 2 reflect two levels of selfenhancement within identity - the personal and the group level, respectively.

\section{Study 2: Effect of Ingroup-Enhancement vs. Outgroup-Enhancement on Racism}

Study 2 extended Study 1 in three different ways. First, we looked at a different level of identity. That is, rather than targeting self- and other-enhancement at the intra- and interpersonal level, Study 2 assessed the connection between intergroup enhancement and prejudice. According to social identity theorists, ingroup promotion also serves to bolster the self (Abrams \& Hogg, 1988; Tajfel \& Forgas, 1981). 
Thus we wondered whether ingroup enhancement would promote more prejudice than outgroup enhancement. Moreover, we thought it was important to test the basic connection between the active process of promoting or praising an outgroup and the outcome of prejudice - in part because very little research has examined this effect (Gonzalez et al., 2015).

Secondly, we included a balanced or objective self (ingroup) condition, where participants focused on both a strength and a weakness of their ingroup. This served to parse out whether self- versus otherenhancement differed from a non-enhancing self-focused condition. This comparison method is arguably more meaningful than a simple no treatment control group because it can rule out the possibility that objective self-evaluation is as beneficial for prejudice reduction as outgroup enhancement. Thus, we sought a stronger test of the other-enhancement effect by assessing whether it produced less prejudice relative to positive as well as objective self-evaluation. Finally, rather than using a repeated measures design as in Study 1, we used an independent groups design to test prejudice between different enhancement groups.

\section{Method}

\section{Design and Procedure}

We randomly assigned participants to one of three reflection conditions: 1 ) ingroup enhancement; 2) outgroup enhancement, and 3) a comparison group that counterbalanced self-enhancement with selfeffacement. We then measured state affect and racism. In the ingroup enhancement condition, participants were first asked to identify their ethnocultural ingroup (or the ethnocultural ingroup to which they identified most), and then to identify a positive trait associated with their ingroup. In the outgroup enhancement condition, we asked participants to consider the outgroup "Black Americans" specifically (since there were no Black Americans in the sample) and then to identify a positive trait associated with that outgroup. In both conditions, participants then wrote about how and why the ingroup/outgroup exemplified the positive trait. For the comparison condition, rather than using an untreated "neutral" 
group, we aimed to counteract the ingroup enhancement procedure by using a counterweighing strategy; we asked participants to identify both a strength and a weakness of their ingroup. We wanted to more rigorously test whether self- versus other-enhancement differed from a condition that was still selffocused, but not necessarily self-enhancing. Thus, participants identified their ethnocultural ingroup (as in condition 1) and then identified both positive and a negative trait associated with their ingroup. They then wrote about how their ingroup exemplified each of these traits. In all conditions, we asked participants to focus on character traits they personally believed described the groups - not physical features or common stereotypes.

\section{Participants}

An a priori power analysis suggested that 146 participants would be needed to find a moderate effect ( $f=.25$; Forscher et al., 2019) with adequate power (0.85). Undergraduates $(\mathrm{N}=169)$ from a small northeastern university participated for course credit. Participants' mean age was 19.300 years (SD=2.451) and $41 \%$ identified as female. Most were American Citizens (93\%) and white (90\% white; $4 \%$ Latinx, $2 \%$ East Asian). We removed ten participants from further analyses because a) they could not identify a positive trait of the outgroup $(n=2) ;$ b) they could not identify a negative trait of their ingroup ( $n=2) ; c)$ they identified physical rather than personality traits associated with the ingroup or outgroup $(n=4)$, or; $d)$ they belonged to the outgroup under study $(n=2)$. The final sample consisted of 159 participants.

\section{Measures}

Manipulation: Ingroup-Enhancing vs. Outgroup-Enhancing Reflections. Participants identified and reflected on an either an ingroup strength (pro-self), an outgroup strength (pro-other), or both a strength and a weakness of their ingroup (objective self). In the pro-self condition and the objective self condition, participants first identified their ethnocultural ingroup before identifying attributes of their ingroup. Thus, ingroup identity was variable. In the pro-other condition, participants (none of whom were Black) were asked to identify a positive attribute of the group Black Americans. All participants then 
explained why and how the attribute(s) described the ingroup or outgroup. We include all experimental materials in the online appendix.

Positive and Negative Affect. We measured both positive and negative affect using 8 items from the Positive and Negative Affect Schedule (Watson et al., 1988), including "happy", "excited", "pleased", "distressed", "upset", "hostile", "worried", and "ashamed". We assessed state affect on a scale from 1 (not at all) to 5 (extremely). Internal consistency was adequate for both positive $(\alpha=.850)$ and negative $\operatorname{affect}(\alpha=.785)$.

Racism. We measured racism toward Black people using ten items from the Symbolic Racism Scale (Henry \& Sears, 2002). This scale assesses the denial of current-day discrimination against Black Americans (e.g., "How much discrimination against black people do you feel there is in society today, limiting their chances to get ahead?"), and the perception of Black Americans as demanding too much from society (e.g., "Black people are getting too demanding in their push for equal rights."). The scale shows good psychometric properties, and explains white people's racial policy preferences considerably better than do traditional racial attitudes or political predispositions (Henry \& Sears, 2002). In the current sample, reliability was minimally adequate $(\alpha=.673)$. Racism scores were summed.

\section{Results and Discussion}

\section{Preliminary Analysis}

Participants' reflections were diverse and showed good face validity. When reflecting on positive ingroup attributes (i.e., in both the ingroup enhancement condition and the balanced comparison condition), participants described their (non-Black) ingroup as "hardworking" (22\%); "compassionate/caring" (18\%); "energetic/happy" (13\%); “open” (12\%); “intelligent" (10\%); "strong/confident" (6\%); "moral" (6\%); and various other traits including polite, humble, free, innovative, and charitable. Participants in the outgroup enhancement condition described the outgroup (Black Americans) as "caring/nice" (26\%); "hardworking" (21\%); "passionate/energetic" (15\%); "talented/artistic" 
(11\%); "loyal" (6\%); "humble" (6\%); "proud" (6\%); and various other attributes including smart, polite, and rich in culture. When asked to identify negative ingroup traits as part of the counterweighted condition, participants said their (non-Black) ingroup was "egocentric/narcissistic" (26\%); "entitled" (25\%); "ethnocentric/intolerant/prejudiced" (17\%); "mean/arrogant" (9\%); "conservative/afraid of change" (7.5\%); "money-focused" (6\%); and "obnoxious/loud" (6\%). On average, participants wrote two to three sentences describing the ingroup or outgroup.

For measured variables, data appeared to satisfy assumptions of normality and there were no univariate or multivariate outliers. We present descriptive statistics and correlations for the measured variables in Table 2. Notably, neither positive nor negative affect was associated with racism.

Table 2. Descriptive Statistics and Correlations for Measured Variables in Study 2

\begin{tabular}{l|lll}
\multicolumn{1}{l}{ Positive Affect } & Negative Affect & Racism \\
\hline Mean & 2.480 & 1.839 & 30.164 \\
Standard Deviation & .965 & .743 & 8.679 \\
Skewness & .239 & .943 & .064 \\
Kurtosis & -.933 & .223 & -.841 \\
Correlations & & & \\
$\quad$ Positive Affect & & -.071 & .072 \\
Negative Affect & & & -.016
\end{tabular}

Note. Theoretical range is 1-5 for affect scores and 10-60 for racism scores.

\section{Main Analysis}

We tested the hypothesis that participants would show less prejudice toward the outgroup after focusing on that outgroup's strengths, compared to focusing on strengths of the ingroup or an objective self condition. We also tested the effect of condition on positive and negative affect, and verified whether this mediated the effect of enhancement type on prejudice. Data and code are available here. 
We first examined the effect of the manipulation on state affect. There was no effect of condition on positive affect $(F<1)$, but condition did influence negative affect, $F(1,156)=3.725, p=.026, \eta_{p}{ }^{2}=.046$, such that those in the outgroup-enhancement condition reported significantly less negative affect $(M=1.617 ; S D=.714)$ than those in the comparison condition $(M=2.015 ; S D=.778), F(1,98)=7.042, p=.009$, $\eta_{\mathrm{p}}{ }^{2}=.067$, and only slightly less negative affect than those in the ingroup enhancement condition $(\mathrm{M}=1.858 ; \mathrm{SD}=.700), \mathrm{F}(1,104)=3.039, \mathrm{p}=.084, \mathrm{n}_{\mathrm{p}}^{2}=.028$

We then conducted an analysis of variance to examine the impact of the reflection task on racism. We display results in Figure 1. The overall effect of condition on racism was significant, $F(2,156)=3.061$, $\mathrm{p}=.048, \eta_{\mathrm{p}}{ }^{2}=.038$. More importantly, planned comparisons of main effects showed that those in the outgroup enhancement condition reported less racism $(M=27.574 ; S D=8.777)$ than those in the ingroup enhancement condition $(M=31.119 ; S D=8.485), F(1,102)=5.803, p=.018, \eta_{p}{ }^{2}=.054$, and those in the objective self condition $(M=31.396 ; S D=8.472), F(1,96)=4.937, p=.029, \eta_{p}^{2}=.049$. Racism did not differ between the ingroup enhancement condition and the objective self condition $(F<1, p=.882)$ - suggesting that self-enhancement did not elicit more racism than a combination of positive and negative selfevaluation.

To assess the mediating roles of both positive and negative affect, we contrasted otherenhancement against self-enhancement and self-objectivity (using a dummy coding procedure) to predict affect and racism. As before, other-enhancement lowered racism compared to the other two conditions, $\mathrm{B}=-3.846, \mathrm{SE}=1.518,95 \% \mathrm{Cl}[-6.844,-.847), \mathrm{t}(156)=-2.534, \mathrm{p}=.012$. However, neither positive nor negative affect mediated this effect $(\beta=.066, p=.529$ and $\beta=-.051, p=.403$ for indirect effects of positive and negative affect, respectively). In line with Study 1, this suggests the palliative effect of otherenhancement is not sufficient to explain why it lowers racism compared to self-enhancement and selfobjectivity. 
Findings from Study 2 validate and extend results of Study 1 . Whereas Study 1 showed that otherenhancement produces less implicit bias relative to self-enhancement within participants, Study 2 suggests that those who engaged in outgroup enhancement showed less racism than those who engaged in ingroup enhancement as well as those who engaged in more balanced ingroup evaluation. Said differently, an objective view of self is no more protective against prejudice than self-enhancement. The link between outgroup enhancement and racism was not explained by changes in affect - although outgroup enhancement indeed lessened negative affect relative to ingroup enhancement and the comparison condition.

\section{Study 3: Construct Validation Exploring Individual Differences}

The purpose of Study 3 was twofold. First, we aimed to validate the lab findings from Studies 1 and 2. That is, we sought to conceptually corroborate the link between other-enhancement and prejudice by looking at individual differences in these general constructs. Thus, we assessed associations between the tendency to enhance the self versus others, on one hand, and racism and sexism on the other.

Our second goal was to examine an important aspect of personality thought to underlie the degree to which one is egoistic versus uplifting of others: humility. Humility is hypo-egoic and reflects low self-focus (Leary \& Guadagno, 2011). A growing body of research on dispositional humility suggests that humble people have a balanced and objective view of the self; they also lack arrogance and appreciate others' worth (Chancellor \& Lyubomirsky, 2013; Davis et al., 2011; Tangney, 2002). Indeed, those high in humility tend to focus more on others and their community than on themselves (Tangney, 2000). We therefore expected humility to show diametrically opposing links to self-versus other-enhancement tendencies - positively linking to other-enhancement, but negatively linking to self-enhancement. In turn, we expected other-enhancement, but not self-enhancement, to be a protective factor against both racism and sexism. We therefore examined the mediating roles of self- versus other-enhancement tendencies in the link between humility and each type of prejudice - although only in a correlational manner. 


\section{Method}

\section{Participants and Procedures}

Participants were undergraduates $(\mathrm{N}=380)$ at a small university in the northeastern United States who completed a 10 minute survey for partial course credit. Their mean age was 19.194 years (SD=1.367) and they were mostly male (67\% male; $32 \%$ female; $1 \%$ nonbinary) and white ( $85 \%$ white; $6 \%$ East Asian; 3\% Latinx/Hispanic; 2\% Biracial; 1.5\% Black).

\section{Measures}

Tendencies toward Self-Enhancement vs. Other-Enhancement. To date, there are no published measures of the tendency to enhance others. Although imperfect, we created four items to measure each type of enhancement tendency, to demonstrate their validity beyond the lab manipulation in Studies 1 and 2. Self-enhancement items included "I think of myself a bit too highly"; "I do not consider myself to be self-centered" (reverse-scored); "I have a bit of a big ego"; and "I do not consider myself to be conceited" (reverse-scored). Other-enhancement items reflected the extent to which one thinks about/is respectful of others [i.e., "I am genuinely interested in others"; "I am open to seeing things from other people's perspectives"; "I am respectful of others"; "I don't really like doing things for others" (reverse-scored)]. Internal consistency was $\alpha=.737$ for self-enhancement and $\alpha=.626$ for other-enhancement. Both measures used a Likert scale ( 1 = disagree completely; 6 = agree completely).

Humility. We measured humility using the Honesty-Humility scale from the HEXACO (Lee \& Ashton, 2004). Considered to be a cardinal personality trait along with extraversion, emotionality, agreeableness, conscientiousness, and openness to experience, honestly-humility taps into the extent to which individuals are genuine and modest, avoiding of corruption, and uninterested in wealth or special treatment. This measure targets four dimensions of honesty-humility, including sincerity, modesty, greedavoidance, and fairness. Items were measured on a Likert scale from 1 (disagree completely) to 5 (agree completely). The overall personality dimension showed good internal consistency $(\alpha=.787)$. 
Racism. We used the full 16-item Symbolic Racism Scale (see Study 2 for a description). We standardized and then averaged racism scores. Internal consistency was $\alpha=.773$.

Sexism. We used the eight item Modern Sexism Scale (Swim, Aiken, Hall, \& Hunter, 1995) to measure paternalistic attitudes toward women, including the denial of continued discrimination (e.g., "Society has reached the point where women and men have equal opportunities for achievement"), and antagonism toward women's demands (e.g., "It is easy to understand the anger of women's groups in America"; reverse-scored). Items were measured on a Likert scale from 1 (disagree completely) to 6 (agree completely). Internal consistency of the overall scale was very good $(\alpha=.859)$.

\section{Results}

\section{Preliminary Analysis}

Data were normal and we did not detect any outliers. We found missing data points, however these were less than $10 \%$ of the total data and thus judged to be missing at random. Inspection of descriptive statistics showed that participants moderately endorsed all variables (see Table 3).

Table 3. Descriptive Statistics for Variables in Study 3

\begin{tabular}{l|lllll}
\multicolumn{1}{c}{} & $\begin{array}{l}\text { Self- } \\
\text { Enhancement }\end{array}$ & $\begin{array}{l}\text { Other- } \\
\text { Enhancement }\end{array}$ & Humility & Racism & Sexism \\
\hline Mean & 3.004 & 4.323 & 4.522 & 3.073 & 2.882 \\
SD & .847 & .576 & .513 & .682 & .999 \\
Skewness & .259 & -.397 & -.131 & .210 & .412 \\
Kurtosis & -.495 & .126 & -.188 & .078 & .134
\end{tabular}

Note. Theoretical range for self-enhancement, other-enhancement, perspective taking, humility and racism is 1-6. Theoretical Range for sexism is 1-5.

Correlations revealed a meaningful pattern (see Table 4), such that self-enhancement related inversely to other-enhancement; humility was negatively associated with self-enhancement, racism, and 
sexism, and positively associated with other-enhancement; and finally, self-enhancement linked positively to both forms of prejudice whereas other-enhancement linked inversely to racism and sexism.

Table 4. Correlations among variables in Study 3

\begin{tabular}{|c|c|c|c|c|}
\hline & $\begin{array}{l}\text { Other- } \\
\text { Enhancement }\end{array}$ & Humility & Racism & Sexism \\
\hline Self-Enhancement & $-.400 * * *$ & $-.403 * * *$ & $.172 * * *$ & $.229 * * *$ \\
\hline Other- Enhancement & & $.331 * * *$ & $-.246 * * *$ & $-.363 * * *$ \\
\hline Humility & & & $-.300 * * *$ & $-.351 * * *$ \\
\hline Racism & & & & $.613 * * *$ \\
\hline
\end{tabular}

Note. ${ }^{*} \mathrm{p}<.05 ;{ }^{* *} \mathrm{p}<.01 ;{ }^{* * *} \mathrm{p}<.001$

\section{Main Analysis}

We sought three main analytical objectives: 1 ) to verify the links between self- versus otherenhancement and prejudice, and 2) to ascertain the association between humility and self- and otherenhancement and prejudice, and; 3 ) to test the mediating roles of self- versus other-enhancement in explaining the association between humility and prejudice. Data and code are available here.

We used SPSS PROCESS (Model 4) to specify tests of direct and indirect effects of humility on both racism and sexism ${ }^{3}$. We present the final model with standardized path coefficients in Figure 2 . HonestyHumility was negatively related to self-enhancement, $\mathrm{B}=-.658, \mathrm{SE}=.081,95 \% \mathrm{Cl}[-.816,-.499], \mathrm{t}(360)=-$ 8.171, $\mathrm{p}<.00001$, and positively related to other-enhancement, $\mathrm{B}=.368, \mathrm{SE}=.056,95 \% \mathrm{Cl}[.257,479]$, $t(360)=6.511, p<.00001$. Honesty-Humility was also negatively related to both racism and sexism after controlling for the effects of self and other-enhancement $(B=-.341, S E=.073,95 \% \mathrm{Cl}[-.486,-.197, \mathrm{t}(360)=-$ 4.660, $p<.00001$ for racism, and $B=-.524, S E=.104,95 \% \mathrm{Cl}[-.729, .320], t(360)=-5.034, p<.00001$ for sexism). Self-enhancement was not uniquely related to either racism or sexism (ts $<1)$, rather, other-

\footnotetext{
${ }^{3}$ Although we tested two models - one for each outcome (racism and sexism), we present them together here for ease of interpretation. Note that estimates of the links between the predictors and mediators were identical across models.
} 
enhancement was negatively associated with both forms of prejudice $[B=.179, S E=.066,95 \% \mathrm{Cl}[.309$, $.048], \mathrm{t}(360)=-2.695, \mathrm{p}=.007$ for racism, and $\mathrm{B}=-.486, \mathrm{SE}=.092,95 \% \mathrm{Cl}[-.667,-.305], \mathrm{t}(360)=-5.277$, $p<.00001$ for sexism]. Finally, although correlational only, other-enhancement accounted for the link between humility and racism, $\mathrm{B}=-.066, \mathrm{SE}=.030,95 \% \mathrm{Cl}[-.133,-.014]$, as well as between humility and sexism, $B=-.154, \mathrm{SE}=.047,95 \% \mathrm{Cl}[-.260,-.076]$. Results support findings from Studies 1 and 2 suggesting that other-enhancement negatively relates to prejudice. Contrary to our prediction, self-enhancement was not uniquely associated with prejudice. We also show here that humility is a key trait associated with self versus other-enhancement, and that humility links to racism and sexism - both directly as well as indirectly through other-enhancement. Importantly, these correlational findings help to corroborate the constructs of self- and other-enhancement at the individual difference level by showing expected relationships with prejudice and humility.

\section{General Discussion}

We provide support for our hypothesis that other-enhancement should lead to less prejudice than both self-enhancement and more objective self-focus. Study 1 used a repeated measures design to show that individuals report less implicit bias when reflecting on the positive traits of close others, compared to when they reflect on their own positive traits. In Study 2 we extended self-enhancement to the level of group identity using an independent groups design to show that those who enhanced an outgroup

subsequently showed less racism compared to those who enhanced their ingroup and those who engaged in more objective ingroup evaluation.

Although more research is needed, the finding that a simple mental exercise in outgroup enhancement ameliorates prejudice is important and novel (Gonzalez et al., 2015). It could be a very impactful and practical prejudice reduction strategy, and one that is positive and proactive (i.e., toward the appreciation of others), rather than negative and restrictive (i.e., against the defect of prejudice). Indeed, recent evidence suggests that individuals prefer prejudice reduction strategies that are 
promotion-oriented toward inclusion and valuing, rather than prevention-focused around self-correction (Al-Khouja et al., 2021; Legault, Gutsell, \& Inzlicht, 2011). Additionally, the current intervention is personal and self-driven. That is, participants identified and constructed the content of the manipulation themselves. Often in prejudice reduction research, participants are exposed to predetermined stimuli (e.g., anti-prejudice messages or images) that are directly aimed at controlling or molding their outgroup attitudes, and these are often met with mixed results (e.g., Lai, Hoffman, \& Nosek, 2013; Paluck \& Green, 2009). Our use of participants' self-determined assessments may have led to more authenticity and absorption in the other-enhancement process, which may have accounted for its success. Because our prejudice reduction strategy was self-directed and positive, rather than imposing or shaming, it may be more effective for those resistant to change. Future work might investigate this question.

We validated these experimental results using a correlational approach. In line with our expectations, items related to other-enhancement were negatively associated with racism and sexism, whereas traits related to self-enhancement were unrelated to racism and sexism. Although only correlational in nature, Study 3 also aligns with past research suggesting that dispositional humility is likely an important personality trait that facilitates the enhancement of others and prevents self-enhancement, or the promotion of self over others (e.g., Chancellor \& Lyubomirsky, 2013; Davis et al., 2011). We contribute to past research on interpersonal humility by showing that it positively links to the enhancement of others and negatively links to prejudice.

This work joins a small but growing area of research on the social importance of thinking about others' positive traits (e.g., Rexwinkel et al., 2011; Scholl et al., 2017). Unlike past research however, we specifically examine the intergroup effects of this cognitive process. Given the challenge and importance of improving intergroup attitudes, the current finding is noteworthy. By targeting a simple and common cognitive activity - i.e., reflecting on the positive qualities of others - implicit and explicit biases seem to lessen at least compared to self-enhancement and self-objectivity. This work expands past research by 
showing that other-enhancement has carryover effects into intergroup bias. That is, whereas previous studies focused on the direct effect of enhancing others on attitudes toward those same others (Harinck \& Duckman, 2019), we show in Study 1 that merely turning focus toward the positive qualities of others crosses domains to improve implicit racism.

At the same time, we provide evidence of this effect at the level of group identity as well, showing that both interpersonal and intergroup other-enhancement lessen prejudice compared to selfenhancement. This latter finding is important because it suggests that a simple process of reflecting on outgroup strengths may lessen prejudice - to our knowledge, no other studies have tested this effect. Nonetheless, this idea builds on important past research describing the importance of mental simulation in attitudinal and behavioral change in the intergroup domain (Crisp, Birtel, \& Meleady, 2011). In line with past research supporting the importance of imagined or simulated intergroup interactions in reducing prejudice (Crisp \& Turner, 2009), we show that the mental exercise of envisioning the positive qualities of an outgroup can also be a mechanism for positive change.

In addition to highlighting the social importance of other-enhancement, we also offer some insight into the role of self-enhancement in prejudice. Researchers traditionally assumed that measures of selfenhancement would predict ingroup favoritism, but this link has not received clear support (Rubin \& Hewstone, 1998). Here, we show that while self-enhancement produces greater prejudice than otherenhancement, it does not increase prejudice relative to objective self-evaluation. Taken with results from Study 3 showing that moderate self-enhancement is not connected to prejudice, it may be the case that self-enhancement is more likely to link to ingroup favoritism than outgroup derogation per se (see Brewer, 1999). In contrast, other-enhancement seems to be negatively related to outgroup derogation. Future research should examine these distinctions, and indeed more research is needed to understand the precise ways in which enhancement type is related to prejudice. Although we tested for the mediating role of affect because we thought positive feelings toward others might lift mood and thereby promote 
more positive and egalitarian outgroup attitudes, we did not find evidence of this mediating effect.

Indeed, it may be the case that the cognitive procedure of calling to mind others' positive traits does not lessen prejudice through an affective pathway, but rather a direct cognitive one. Alternatively, we may have failed to find a mediating effect of affect because measured direct, self-focused emotional states (e.g., "I feel happy/sad/anxious"), which may not adequately capture the other-focused affect involved in thinking about others' positive qualities. Indeed, other-enhancement may affect other-focused emotions like appreciation, admiration, and gratitude - rather than self-focused emotions.

Admiration, in particular, may be a possible mechanism driving the effects of other-enhancement. To date, only a handful of empirical studies on intergroup admiration have been published (Algoe \& Haidt, 2009; Onu, Kessler, \& Smith, 2016). However, initial evidence suggests that it is an important aspect of positive intergroup attitudes. Specifically, research shows that when people admire a minority outgroup, they exhibit more desire to reject the social status quo (Sweetman, Spears, Livingstone, \& Manstead, 2013), and admiration for an outgroup can explain why intergroup contact works to reduce prejudice (Seger, Banerji, Park, Smith \& Mackie, 2017). Other work suggests that practicing kindness can reduce implicit bias via other-regarding emotion (Stell \& Farsides, 2016). Therefore, follow-up studies should test the connection between other-enhancement strategies/processes and the emotional experience of admiration. This promises to be an important area of inquiry to promote prejudice reduction and positive intergroup outcomes.

We note various caveats of the current research. It is important to clarify that we did not use a self-affirmation manipulation (as per Sherman \& Cohen, 2002) and therefore it is difficult to integrate these findings within the self-affirmation literature. Self-affirmation, unlike self-enhancement here, has previously linked to a reduction in prejudice because it serves to preserve self-esteem in the face of selfthreat. That is, it serves a palliative function by assuaging integrity insecurity (e.g., Proulx, Inzlicht, \& Harmon-Jones, 2012). In the current work, we do not use self-affirmation to curb defensive responding 
but rather compare self-enhancement to other-enhancement in the absence of threat, to measure subsequent effects on prejudice. However, future research might integrate self-affirmation with the current paradigm to ascertain whether enhancing others offers the same compensatory effects on prejudice (and other intergroup outcomes) after self-threat.

Relatedly, this research suggests a need to attend more carefully to the different effects of affirmation versus enhancement in future studies. Whereas affirmation typically centers on the activation of the core self through personal values, enhancement involves only the focus on positive attributes. Since researchers have noted the many benefits of self-affirmation, from positive health outcomes to more satisfying interpersonal relationships (Cohen \& Sherman, 2014), it will be important to ascertain whether these benefits recede when individuals engage in self-enhancement or self-aggrandizement.

Other limitations are worth noting. Importantly, we only used one control condition (in Study 2). The use of additional conditions, including neutral conditions, would be useful in determining whether other-enhancement produces less prejudice than other cognitive strategies both related and unrelated to the self. Also, although we attempted to represent diverse methodologies and measures, and we relied on appropriate sample sizes so as not to overestimate or underestimate our results, we lack data to ascertain the precise mechanisms through which other-enhancement elicits its effects; this is a key goal of future investigation. As noted previously, emotional mediators such as admiration, and cognitive factors like openness and flexibility, might be worth exploring next. Future research should also achieve a deeper understanding of whether some forms of other-enhancement may be more effective than others; for instance, we show that both interpersonal other-enhancement and group-level other-enhancement may protect against prejudice, but we do not test which effect is stronger (or for whom). In a final note of caution, although this research is hopeful in suggesting that active positive thinking about others and outgroups may ameliorate prejudice; the flipside of this may be that engaging in negative reflection about 
others could actually worsen prejudice. We therefore must consider potential downsides to reflecting on the traits of others.

\section{Conclusion}

Whereas many social and personality psychologists have discussed the ubiquity of self-

enhancement, relatively few have contrasted it with its counterpart - the enhancement of others. In this research, we show that prejudice lessens when people attend to others' positive attributes rather than their own positive attributes. We join a line of research that emphasizes the importance of appreciating others in order to foster healthier relationships and a more kind, just, and fair society. Given the universality of egotism and self-promotion, as well as the ubiquity of prejudice and mistrust in all spheres of life, insight into strategies that promote the enhancement, affirmation, and admiration of other people cannot be overlooked. 


\section{References}

Abrams, D., \& Hogg, M. A. (1988). Comments on the motivational status of self-esteem in social identity and intergroup discrimination. European Journal of Social Psychology, 18(4), 317-334.

Algoe, S. B., \& Haidt, J. (2009). Witnessing excellence in action: The 'other-praising' emotions of elevation, gratitude, and admiration. The Journal of Positive Psychology, 4(2), 105-127.

Algoe, S. B., Haidt, J., \& Gable, S. L. (2008). Beyond reciprocity: Gratitude and relationships in everyday life. Emotion, 8(3), 425.

Alicke, M. D., \& Govorun, O. (2005). The better-than-average effect. The Self in Social Judgment, 1, 85106.

Alicke, M. D., Klotz, M. L., Breitenbecher, D. L., Yurak, T. J., \& Vredenburg, D. S. (1996). Personal contact, individuation, and the better than-average effect. Journal of Personality and Social Psychology, 68, 804-825.

Alicke, M. D., \& Sedikides, C. (2011). Handbook of Self-Enhancement and Self-Protection. New York, NY: Guilford Press.

Al-Khouja, M., Weinstein, N., Moin, T., Legate, N., Graham, L., Moller, A., Legault, L. (2021). How to Deliver Effective \& Engaging Equality, Diversity, and Inclusion Training in Policing. University of Reading.

Ames, D. R., Rose, P., \& Anderson, C. P. (2006). The NPI-16 as a short measure of narcissism. Journal of Research in Personality, 40(4), 440-450. 
Anderson, J., \& Cheers, C. (2018). Does the dark triad predict prejudice?: The role of machiavellianism, psychopathy, and narcissism in explaining negativity toward asylum seekers. Australian Psychologist, 53(3), 271-281.

Aron, A., Aron, E. N., Tudor, M., \& Nelson, G. (1991). Close relationships as including other in the self. Journal of Personality and Social Psychology, 60(2), 241.

Asendorpf, J. B., \& Ostendorf, F. (1998). Is self-enhancement healthy? Conceptual, psychometric, and empirical analysis. Journal of Personality and Social Psychology, 74(4), 955.

Baumeister, R. F., Stillwell, A., \& Wotman, S. R. (1990). Victim and perpetrator accounts of interpersonal conflict: Autobiographical narratives about anger. Journal of Personality and Social Psychology, 59(5), 994.

Brewer, M. B. (1999). The psychology of prejudice: Ingroup love and outgroup hate? Journal of social issues, 55(3), 429-444.

Brown, S. L., Chen, X., Coakley, R. G., Hlabangana, N., Oakley, E., \& Trenholme, S. (2019). Does otheraffirmation increase self-directed exposure to and persuasiveness of a threatening anti-alcohol message? British Journal of Health Psychology, 24(3), 497-514.

Chancellor, J., \& Lyubomirsky, S. (2013). Humble beginnings: Current trends, state perspectives, and humility hallmarks. Social and Personality Psychology Compass, 7, 819-833.

Cohen, G. L., \& Sherman, D. K. (2014). The psychology of change: Self-affirmation and social psychological intervention. Annual Review of Psychology, 65, 333-371.

Crawford, J. R., \& Henry, J. D. (2004). The Positive and Negative Affect Schedule (PANAS): Construct validity, measurement properties and normative data in a large non-clinical sample. British Journal of Clinical Psychology, 43(3), 245-265. 
Crisp, R. J., Birtel, M. D., \& Meleady, R. (2011). Mental simulations of social thought and action: Trivial tasks or tools for transforming social policy? Current Directions in Psychological Science, 20, 261264.

Crisp, R. J., \& Turner, R. N. (2009). Can imagined interactions produce positive perceptions? Reducing prejudice through simulated social contact. American Psychologist, 64, 231-240.

Davis, D. E., Hook, J. N., Worthington Jr, E. L., Van Tongeren, D. R., Gartner, A. L., Jennings, D. J., \& Emmons, R. A. (2011). Relational humility: Conceptualizing and measuring humility as a personality judgment. Journal of Personality Assessment, 93(3), 225-234.

Davis, M. H. (1980). A multidimensional approach to individual differences in empathy. JSAS Catalog of Selected Documents in Psychology, 10, 85.

Davis, M. H. (2018). Empathy: A social psychological approach. Routledge.

Deci, E. L., \& Ryan, R. M. (2014). Autonomy and need satisfaction in close relationships: Relationships motivation theory. In Human Motivation and Interpersonal Relationships (pp. 53-73). Springer, Dordrecht.

Fagley, N. S. (2016). The construct of appreciation: It is so much more than gratitude. In Carr, D. (Ed.), Perspectives on Gratitude: An Interdisciplinary Approach (pp. 70-84). New York, NY: Routledge.

Finlay, K. A., \& Stephan, W. G. (2000). Improving intergroup relations: The effects of empathy on racial attitudes Journal of Applied Social Psychology, 30(8), 1720-1737.

Fein, S., \& Spencer, S. J. (1997). Prejudice as self-image maintenance: Affirming the self through derogating others. Journal of Personality and Social Psychology, 73, 31-44. 
Forscher, P. S., Lai, C. K., Axt, J. R., Ebersole, C. R., Herman, M., Devine, P. G., \& Nosek, B. A. (2019). A meta-analysis of procedures to change implicit measures. Journal of Personality and Social Psychology, 117(3), 522-559.

Gonzalez, K. A., Riggle, E. D. B., \& Rostosky, S. S. (2015). Cultivating positive feelings and attitudes: A path to prejudice reduction and ally behavior. Translational Issues in Psychological Science, 1(4), 372381.

Greenwald, A. G., McGhee, D. E., \& Schwartz, J. L. (1998). Measuring individual differences in implicit cognition: The Implicit Association Test. Journal of Personality and Social Psychology, 74, 14641480.

Greenwald, A. G., Nosek, B. A., Banaji, M. R. (2003). Understanding and using the Implicit Association Test: I. An improved algorithm. Journal of Personality and Social Psychology, 85, 197-216.

Greenwald, A. G., Poehlman, T. A., Uhlmann, E., \& Banaji, M. R. (2009). Understanding and using the Implicit Association Test: III. Meta-analysis of predictive validity. Journal of Personality and Social Psychology, 97, 17-41.

Hair, J. F., Black, W. C., Babin, B. J., \& Anderson, R. E. (2010). Multivariate data analysis: Pearson College Division.

Harinck, F., \& Druckman, D. (2019). Values and interests: Impacts of affirming the other and mediation on settlements. Group Decision and Negotiation, 28(3), 453-474.

Henry, P. J., \& Sears, D. O. (2002). The Symbolic Racism 2000 scale. Political Psychology, 23(2), 253-283.

Hodson, G., Hogg, S. M., \& Maclnnis, C. C. (2009). The role of "dark personalities" (narcissism, Machiavellianism, psychopathy), Big Five personality factors, and ideology in explaining prejudice. Journal of Research in Personality, 43(4), 686-690. 
Huntsinger, J. R., Sinclair, S., Dunn, E., \& Clore, G. L. (2010). Affective regulation of stereotype activation: It's the (accessible) thought that counts. Personality and Social Psychology Bulletin, 36(4), 564577.

Lai, C. K., Hoffman, K. M., \& Nosek, B. A. (2013). Reducing implicit prejudice. Social and Personality Psychology Compass, 7(5), 315-330.

Lambert, A. J., Khan, S. R., Lickel, B. A., \& Fricke, K. (1997). Mood and the correction of positive versus negative stereotypes. Journal of Personality and Social Psychology, 72, 1002-1016.

Leary, M. R., Diebels, K. J., Davisson, E. K., Jongman-Sereno, K. P., Isherwood, J. C., Raimi, K. T., ... \& Hoyle, R. H. (2017). Cognitive and interpersonal features of intellectual humility. Personality and Social Psychology Bulletin, 43(6), 793-813.

Leary, M. R., \& Guadagno, J. (2011). The role of hypo-egoic self-processes in optimal functioning and subjective well-being. In K. M. Sheldon, T. B. Kashdan, \& M. F. Steger (Eds.), Designing Positive Psychology: Taking Stock and Moving Forward (pp. 135-146). New York, NY: Oxford University Press.

Lee, K., \& Ashton, M. C. (2004). Psychometric properties of the HEXACO personality inventory. Multivariate Behavioral Research, 39(2), 329-358.

Legault, L., Gutsell, J. N., \& Inzlicht, M. (2011). Ironic effects of antiprejudice messages: How motivational interventions can reduce (but also increase) prejudice. Psychological Science, 22(12), 1472-1477.

Markus, H. R., \& Kitayama, S. (1991). Culture and the self: Implications for cognition, emotion, and motivation. Psychological Review, 98(2), 224.

Martela, F., \& Ryan, R. M. (2016). The benefits of benevolence: Basic psychological needs, beneficence, and the enhancement of well-being. Journal of Personality, 84(6), 750-764. 
McCullough, M. E., Tsang, J. A., \& Emmons, R. A. (2004). Gratitude in intermediate affective terrain: links of grateful moods to individual differences and daily emotional experience. Journal of Personality and Social Psychology, 86(2), 295.

McQueen A., Klein W.M.P. (2006). Experimental manipulations of self-affirmation: A systematic review. Self and Identity, 5, 289-354.

Mischel, W., Ebbesen, E. B., \& Zeiss, A. M. (1976). Determinants of selective memory about the self. Journal of Consulting and Clinical Psychology, 44(1), 92.

Montoya, A. K., \& Hayes, A. F. (2017). Two condition within-participant statistical mediation analysis: A path-analytic framework. Psychological Methods, 22, 6-27.

Nosek, B. A., Greenwald, A. G., \& Banaji, M. R. (2005). Understanding and using the Implicit Association Test: II. Method variables and construct validity. Personality and Social Psychology Bulletin, 31(2), 166-180.

Paluck, E. L., \& Green, D. P. (2009). Prejudice reduction: What works? A review and assessment of research and practice. Annual Review of Psychology, 60, 339-367.

Paulhus, D. L. (1998). Interpersonal and intrapsychic adaptiveness of trait self-enhancement: A mixed blessing? Journal of Personality and Social Psychology, 74(5), 1197.

Proulx, T., Inzlicht, M., \& Harmon-Jones, E. (2012). Understanding all inconsistency compensation as a palliative response to violated expectations. Trends in Cognitive Sciences, 16(5), 285-291.

O'Mara, E. M., Gaertner, L., Sedikides, C., Zhou, X., \& Liu, Y. (2012). A longitudinal-experimental test of the panculturality of self-enhancement: Self-enhancement promotes psychological well-being both in the West and the East. Journal of Research in Personality, 46, 157-163.

doi:10.1016/j.jrp.2012.01.001 
Onu, D., Kessler, T., \& Smith, J. R. (2016). Admiration: A conceptual review. Emotion Review, 8(3), 218230.

Onu, D., Kessler, T., Andonovska-Trajkovska, D., Fritsche, I., Midson, G. R., \& Smith, J. R. (2016). Inspired by the outgroup: A social identity analysis of intergroup admiration. Group Processes \& Intergroup Relations, 19(6), 713-731.

Ortony A., Clore GL., \& Collins, A. (1988). The cognitive structure of emotion. New York: Cambridge University Press.

Raskin, R., Novacek, J., \& Hogan, R. (1991). Narcissism, self-esteem, and defensive selfenhancement. Journal of Personality, 59(1), 19-38.

Reeve, J. (2014). Understanding Motivation and Emotion (5th ed.). Hoboken, NJ: Wiley.

Rexwinkel, R., Ellemers, N., \& Harinck, F. (2011). Wanneer jij OK bent, ben ik ook OK. Hoe de bevestiging van een ander het oplossen van een waardenconflict vergemakkelijkt [When you are OK, I am OK. How affirming the other helps to resolve a value conflict]. ASPO Jaarboek.

Rubin, M., \& Hewstone, M. (1998). Social identity theory's self-esteem hypothesis: A review and some suggestions for clarification. Personality and Social Psychology Review, 2(1), 40-62.

Schindler, I., Paech, J., \& Löwenbrück, F. (2015). Linking admiration and adoration to self-expansion: Different ways to enhance one's potential. Cognition and Emotion, 29(2), 292-310.

Schindler, I., Zink, V., Windrich, J., \& Menninghaus, W. (2013). Admiration and adoration: Their different ways of showing and shaping who we are. Cognition \& Emotion, 27(1), 85-118. 
Schmitt, D. P., \& Allik, J. (2005). Simultaneous administration of the Rosenberg Self-Esteem Scale in 53 nations: exploring the universal and culture-specific features of global self-esteem. Journal of Personality and Social Psychology, 89(4), 623.

Scholl, A., Sassenberg, K., Scheepers, D., Ellemers, N., \& de Wit, F. (2017). A matter of focus: Powerholders feel more responsible after adopting a cognitive other-focus, rather than a selffocus. British Journal of Social Psychology, 56(1), 89-102.

Schwartz, S. H. (2012). An overview of the Schwartz theory of basic values. Online Readings in Psychology and Culture, 2(1), 2307-0919.

Schwarz, N., \& Clore, G. L. (2007). Feelings and phenomenal experiences. In E. T. Higgins \& A. Kruglanski (Eds.), Social psychology. A handbook of basic principles (2nd ed., pp. 385-407). New York: Guilford.

Sedikides, C., \& Alicke, M. D. (2019). The five pillars of self-enhancement and self-protection. The Oxford Handbook of Human Motivation, 2, 307-319.

Sedikides, C., Gaertner, L., \& Vevea, J. L. (2005). Pancultural self-enhancement reloaded: A meta-analytic reply to Heine (2005). Journal of Personality and Social Psychology, 89(4), 539-551.

Seger, C. R., Banerji, I., Park, S. H., Smith, E. R., \& Mackie, D. M. (2017). Specific emotions as mediators of the effect of intergroup contact on prejudice: Findings across multiple participant and target groups. Cognition and Emotion, 31(5), 923-936.

Sherman, D. K., \& Cohen, G. L. (2002). Accepting threatening information: Self-affirmation and the reduction of defensive biases. Current Directions in Psychological Science, 11, 119 -123.

Stangor, C., \& Thompson, E. P. (2002). Needs for cognitive economy and self-enhancement as unique predictors of intergroup attitudes. European Journal of Social Psychology, 32(4), 563-575. 
Steele, C. M. (1988). The psychology of self-affirmation: Sustaining the integrity of the self. In L. Berkowitz (Ed.), Advances in Experimental Social Psychology (Vol. 21, pp. 261-302). New York, NY: Academic Press.

Stell, A. J., \& Farsides, T. (2016). Brief loving-kindness meditation reduces racial bias, mediated by positive other-regarding emotions. Motivation and Emotion, 40(1), 140-147.

Sweetman, J., Spears, R., Livingstone, A. G., \& Manstead, A. S. (2013). Admiration regulates social hierarchy: Antecedents, dispositions, and effects on intergroup behavior. Journal of Experimental Social Psychology, 49(3), 534-542.

Swim, J. K., Aikin, K. J., Hall, W. S., \& Hunter, B. A. (1995). Sexism and racism: Old-fashioned and modern prejudices. Journal of Personality and Social Psychology, 68(2), 199.

Tajfel, S., \& Forgas, J. P. (1981). Social categorization: Cognitions, values and groups. In J. P. Forgas (Ed.), Social Cognition (pp. 113-140). San Diego, CA: Academic Press.

Tangney, J.P. Humility. In C.R. Snyder \& S.J. Lopez (Eds), Handbook of Positive Psychology. New York: Oxford University Press, 2002, pp. 411-19.

Tangney, J. P. (2000). Humility: Theoretical perspectives, empirical findings and directions for future research. Journal of Social and Clinical Psychology, 19(1), 70-82.

Taylor, S. E., \& Brown, J. D. (1988). Illusion and well-being: A social psychological perspective on mental health. Psychological Bulletin, 103, 193-210.

Todd, A. R., Bodenhausen, G. V., Richeson, J. A., \& Galinsky, A. D. (2011). Perspective taking combats automatic expressions of racial bias. Journal of Personality and Social Psychology, 100(6), 1027. 
Turner, J. C., Hogg, M. A., Oakes, P. J., Reicher, S. D., \& Wetherell, M. S. (1987). Rediscovering the social group: A self-categorization theory. Basil Blackwell.

Van Lange, P. A., De Bruin, E., Otten, W., \& Joireman, J. A. (1997). Development of prosocial, individualistic, and competitive orientations: theory and preliminary evidence. Journal of Personality and Social Psychology, 73(4), 733.

Watson, D., Clark, L. A., \& Tellegen, A. (1988). Development and validation of brief measures of positive and negative affect: The PANAS Scales. Journal of Personality and Social Psychology, 47, 10631070. 
Figure 1. Racism Scores Per Condition

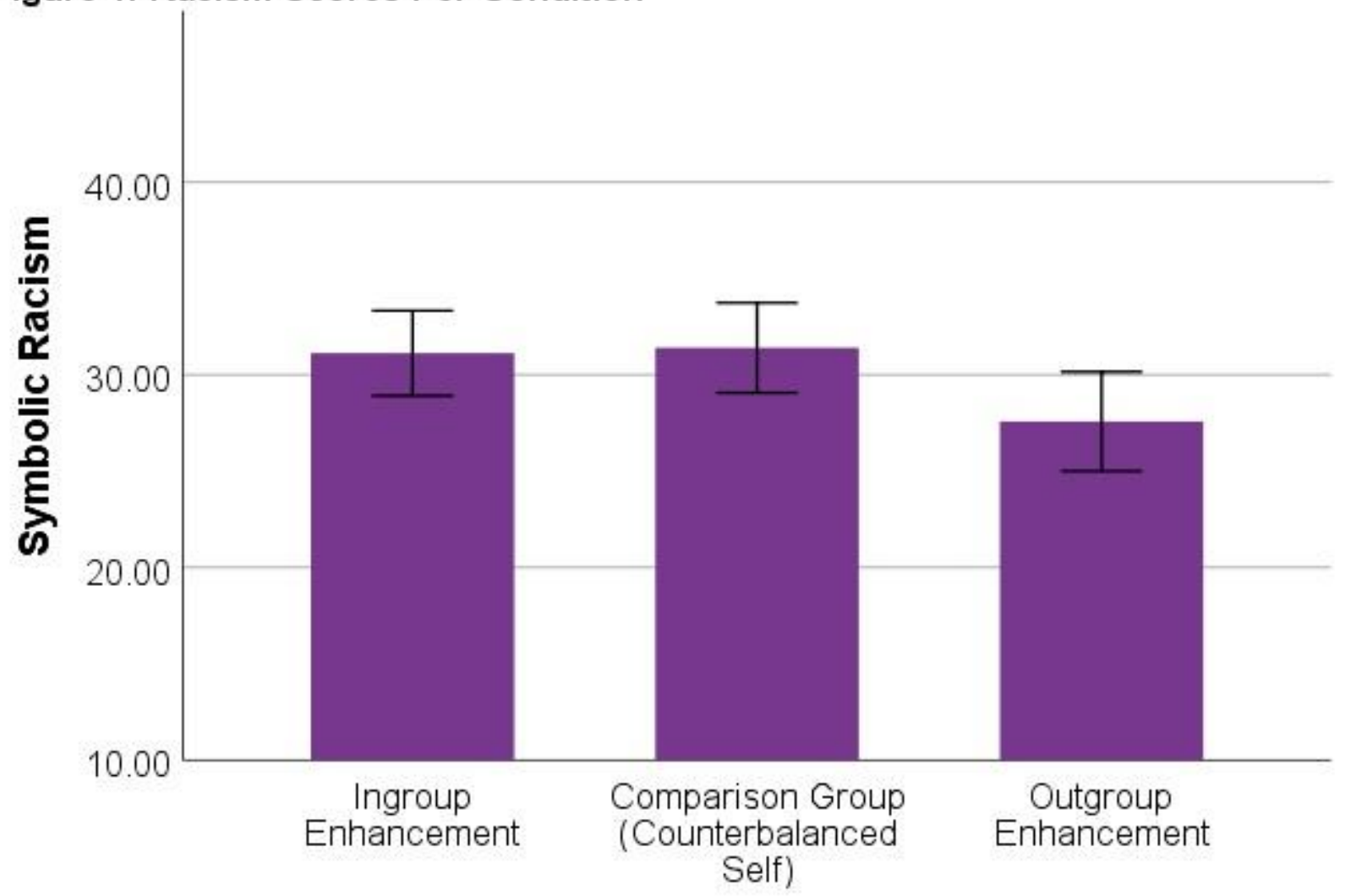

Note. Error bars represent $95 \%$ confidence intervals around the mean. 
Figure 2. Mediating Role of Other-Enhancement in the Link between Humility and Prejudice $(\mathrm{N}=380)$

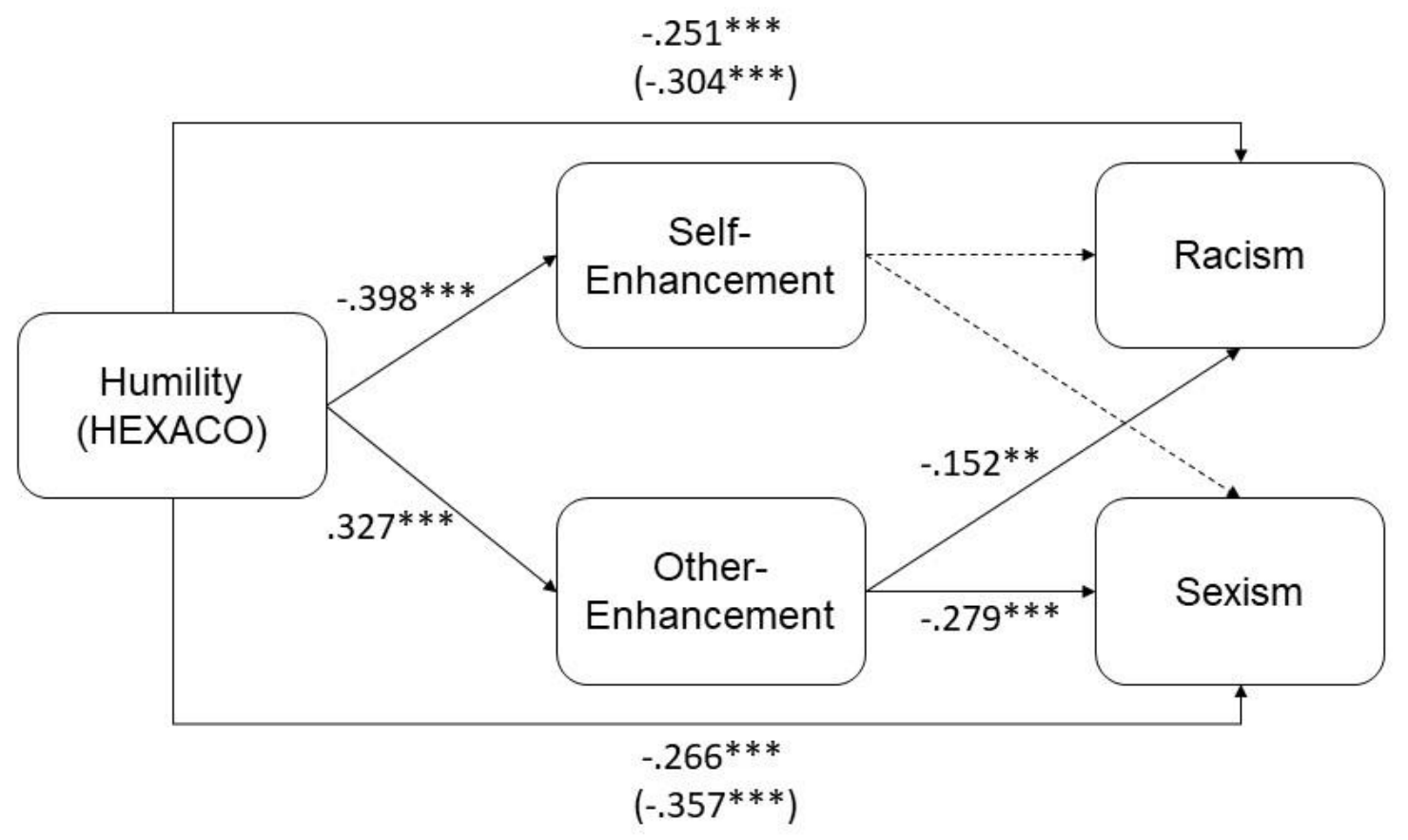

Note. Path coefficients are standardized for interpretation of effect sizes. 